\title{
Assessments of safe medication administration in nursing education
}

\author{
Kelly J. Gonzales \\ UNMC College of Nursing, 985330 Nebraska Medical Center, Omaha, Nebraska \\ Correspondence: Kelly J. Gonzales. Address: UNMC College of Nursing 985330 Nebraska Medical Center, Omaha, \\ Nebraska. Zip Code: 68198-5330 402-968-1258 (cell), 402-559-4111 (office). Email: kelly.gonzales@unmc.edu \\ Received: October 14, 2011 \\ Accepted: November 29, 2011 Published: February 1, 2012 \\ DOI : $10.5430 /$ jnep.v2n1p39 \\ URL: http://dx.doi.org/10.5430/jnep.v2n1p39
}

\section{Abstract}

Background: QSEN has a variety of suggested strategies for teaching safe medication administration. However, they do not have a recommendation for how to assess it. The purpose of this study was to gain information on how safe medication administration is assessed in nursing education.

Methods: A survey was developed to identify methods used by nursing faculty members to assess nursing students' knowledge and skills of safe medication administration. The specific research questions addressed in the survey were: 1) How is safe medication administration assessed prior to students entering the clinical area; 2) How is safe medication administration assessed during clinical; 3) How is knowledge of "right drug" assessed in the classroom and 4) How is knowledge of "right dose" assessed in the classroom setting.

Results: The results of the survey indicated no standardized method for assessing safe medication administration in nursing education.

Conclusions: There is much variation in how and when safe medication administration is assessed in the education setting. There is a need for a valid and reliable comprehensive assessment of safe medication administration in order to evaluate whether nursing students have the knowledge, skills and attitude to safely administrate medications.

\section{Key words}

Education safety, Safe medication administration, Nursing education, Assessments

\section{I ntroduction}

Medication errors are the most common error that occurs in hospital settings ${ }^{[1]}$. It has been estimated that 7000 deaths occur annually due to medication errors ${ }^{[2]}$. Quality and Safety Education for Nurses (QSEN) was formed to identify gaps in nursing education and implement a curriculum to include quality and safety ${ }^{[3]}$. While QSEN has a variety of suggested strategies for teaching safe medication administration, they do not have a recommendation for how to assess it ${ }^{[4]}$. The purpose of this study was to gain information on how safe medication administration is assessed in nursing education by presenting the results of a survey (see Table 1) developed to identify methods used by nursing faculty members to assess nursing students' knowledge and skills of safe medication administration. 
Table 1. Survey for Nursing Education Programs on Safe Medication Administration

\section{Questions}

1. Type of school the nursing program is a part of:

Independent (private) institution

Public institution

2 What nursing degrees does your college or school offer? Mark all that apply.

Bachelor of Science in Nursing (BSN)

Bachelor of Arts with a major in Nursing

Master of Science / Arts in Nursing

Doctorate in Nursing Practice (DNP)

$\mathrm{PhD}$ in Nursing

Other (please describe)

3. What are the number of BSN students that your program typically graduates each year

4. Please identify which of the following methods are used in your nursing program to assess the baccalaureate students' ability to administer medications safely prior to administering medications in the clinical setting. Mark all that apply. Successful completion of a stand-alone pharmacology course Successful completion of nursing course(s) that integrate Pharmacology content Computer-assisted safe medication administration module and exam Examinations that include questions on safe medication administration Medication calculation / mathematical exam Performance assessment in skills laboratory on medication administration Performance assessment prior to clinical Unsure Other (Please describe)

5. Please identify which of the following methods are used in your nursing program to assess the baccalaureate students' ability to administer medications safely while in the clinical setting. Mark all that apply.

Oral review with clinical instructor

Written assignment

Performance assessment during clinical

Unsure

Other (Please describe)

6. Who teaches the pharmacology course content in your nursing program to baccalaureate nursing students? Mark all that apply.

Nursing faculty with nursing degree

Nursing faculty without nursing degree

Non-nursing faculty

Unsure

7. How frequently do the BSN nursing students take a medication calculation exam in your nursing program?

Once during the entire program

Annually

Each semester

Integrated into every nursing exam

Unsure

Other (Please describe) 
Table 1. (Continued.)

\section{Questions}

8. Did you or members of your faculty develop the medication calculation exam used in your nursing program? Yes

No

Unsure

9. What is a passing percentage grade on the medication calculation exam in your nursing program?

10. If the student is not successful on the medication calculation exam, what type of remediation, if any, is the student expected to complete in your nursing program?

11. Is there any additional information you can provide to clarify how your nursing program ensures competency in medication calculations?

12. Is a specific "performance checklist" for safe medication administration used in the skills laboratory, clinical or both in your nursing program? Yes No

13. Is there anything else you would like to include to better describe how your nursing program assesses its baccalaureate students for safe medication administration?

14. Would you be comfortable sharing any of your assessments with the researcher (such as the performance checklist, exams, etc)? If so, please copy the document into the space below, email or send via postal service to the researcher.

\subsection{Review of the literature}

Medication administration has been defined from the Nursing Intervention Classification (NIC) as preparing, giving, and evaluating effectiveness of prescription and nonprescription medications ${ }^{[5]}$. In 1995, the United States Pharmacopeia (USP) formed The National Coordinating Council for Medication Error Reporting and Prevention (NCC MERP) ${ }^{[6]}$. The NCC MERP is an independent body comprised of many national organizations (e.g. American Nurses Association, The Joint Commission, National Council of State Boards of Nursing, and Institute for Safe Medication Practices) that addresses the causes of medication errors and promotes the safe use of medications. In 1999, they issued recommendations to enhance the accuracy of medication administration in the inpatient setting ${ }^{[7]}$. Included in these recommendations is a series of checks that has come to be known as the "five rights." While initially five checks were recommended, this has since expanded to include: clarify orders that cause concern; check to ensure the right medication, in the right dose, to the right person, by the right route using the right dosage form, at the right time, with the right documentation immediately prior to administration; ensure adequate training and competency with medication administration devices; use technology to reduce transcription errors; ensure patient information is available as close to the point of care as possible; ensure medications are labeled properly and check the label a total of three times; discuss the purpose and effects of the medication with the patient/family; monitor for therapeutic and/or adverse effects; consider the environment and its role on patient safety; collect and analyze data with regards to medication errors and near misses; ensure ongoing training of standards of practice related to accurate medication administration; establish policies and procedures for the medication administration process.

A literature review was conducted to locate instruments and other methods for assessing either an individual's performance on any element of safe medication administration or on all elements of safe medication administration within 
the literature. The instruments identified in the articles had varying levels of evidence of validity and reliability, and some of the instruments' psychometric properties included just validity or reliability but not both. Instruments were categorized and the resulting categories including assessing right dose, right drug or else were comprehensive of safe medication administration. No other categories of instruments were found. A discussion of the instruments follows.

\subsection{Medication calculation instruments: Right dose}

Ten of the articles found were specific for assessing the performance of medication calculation ${ }^{[8-17]}$. Medication calculation is an important skill as it assures one of the five rights of safe medication administration: right dose. The most commonly used instrument to assess medication calculation was the Bayne-Bindler Medication Calculation Test, although a total of six instruments were found within the ten articles that assess right dose.

The Bayne-Bindler Medication Calculation Test was initially found to have evidence of content validity and an odd-even split half test of reliability of $0.82{ }^{[9]}$. In their 1997 study, the authors found an internal consistency reliability using Cronbach's alpha was 0.72 for the pretest and 0.74 for the posttest ${ }^{[10]}$. Serembus provided additional evidence of validity and reliability on the Bayne-Bindler Medication Calculation test ${ }^{[17]}$. She found evidence of content validity, and internal consistency reliability using the Kuder-Richardson formula was 0.70 for the pretest and 0.83 for the posttest. Ashby used the Bayne-Bindler Medication Calculation test in her study, but did not provide additional evidence of validity or reliability ${ }^{[8]}$.

A second instrument including two forms for assessing medication calculation abilities was described by Bliss-Holtz ${ }^{\text {[13] }}$. The two forms were reported to have content validity. Internal consistency reliability was calculated with alpha $=0.83$ for Form I and alpha $=0.71$ for Form II when piloting the instrument on 39 nurses, and the other results in a study of 51 nurses were alpha $=0.81$ for Form I and alpha $=0.79$ for Form II. Reliability was obtained by giving both tests in a random order to a convenience sample of 49 nurses, and a Pearson correlation of 0.94 was obtained.

Flynn and Moore developed a 20-item examination consisting of metric-English conversions and medication and intravenous calculations ${ }^{[14]}$. Content validity was established through two separate pilot studies. When 46 subjects participated, the alpha for internal consistency reliability was 0.83 , and was 0.82 in a study with 64 nursing students.

Kohtz and Gowda described a 24-item tool that involved calculating the number of tablets to administer, calculating the number of milliliters to administer, calculating milliliters per hour, and calculating drops per minute ${ }^{[15]}$. The authors state that content validity was established, but no additional information on the psychometric properties of the instrument was provided.

Rainboth and DeMasi described two different instruments in their article ${ }^{[16]}$. The first instrument was a 14-item multiple-choice test, which they established content validity on and the internal consistency reliability was documented as alpha $=0.674$. The second instrument was a 10-item fill-in-the-blank test, which they established content validity on and internal consistency reliability was documented as alpha $=0.135$. The authors conclude the low reliability score for the second instrument could be explained by the large percentage of students who received $100 \%$ on the exam. No further information was included or could be located regarding validity or reliability of either of these instruments.

In summary, six instruments were discussed in the ten articles that were specific to assessing students' or nurses' ability to correctly calculate medication dosage, or assure right dose. The medication calculation test that has been used the most is the Bayne-Bindler Medication Calculation Test. In addition, this instrument had the most reported evidence of established validity and reliability for assessing individual's abilities for correctly calculating medication dosage, which is one aspect of safe medication administration. This is the only instrument identified that was used to assess the preparation of students prior to the administration of medications. 


\subsection{Pharmacology knowledge instrument: Right drug}

Knowledge of pharmacology, or right drug, is an important component of safe medication administration. Ndosi and Newell developed an instrument to assess nurses' knowledge of pharmacology for medications commonly administered on surgical units ${ }^{[18]}$. The authors report the instrument had evidence of face validity and content validity. Reliability assessment for the pharmacology questionnaire was limited to inter-rater reliability and was determined by calculating the intra-class correlation coefficient (ICC). The average ICC for the study was 0.726 with $p=0.001$, indicating the strength of agreement among raters was good. No further evidence of validity or reliability was reported.

\subsection{Comprehensive instruments for safe medication administration}

Hsaio and colleagues developed and validated a questionnaire to measure nurses' knowledge of administering high-alert medications from eight categories: cardiovascular medications, chemotherapeutic agents, narcotics, opiates, anticoagulants, benzodiazepines, neuromuscular blocking agents and electrolytes ${ }^{[19]}$. Face validity and content validity were established. Construct validity was established through the contrasted groups approach using registered nurses and nursing students. Results demonstrated a statistically significant difference in the knowledge scores of participants, and the authors concluded the questionnaire had construct validity. Internal consistency reliability was established for the pilot with an alpha $=0.66(\mathrm{~N}=50)$ and for the study with 305 subjects, the alpha=0.74.

In a separate article, Werab and colleagues discussed two instruments that assess medication administration ${ }^{[20]}$. The first instrument was a 24-question pretest and the second instrument was a 45-question posttest. The posttest had a higher level of difficulty than the pretest. After 27 nurses had completed the instruments, an item analysis of the pretest and posttest was completed. Questions on the pretest frequently missed were reworded or discarded; questions never missed were revised with different distracters. In addition, the pretest was expanded to include questions to assess judgment, critical thinking skills and on the common types of errors at the hospital. After evaluation, the post-test was eliminated entirely and an alternate format was used to assess knowledge retention. No further information regarding the pretest or posttest was provided including overall validity and reliability of the final pretest after changes were made or the rationale for the elimination of the posttest.

The last instrument to be presented, the Safe Administration of Medication (SAM) Scale, was developed to objectively measure performance of the safe administration of medication ${ }^{[21]}$. The SAM Scale was constructed to be administered to associate degree and baccalaureate degree nursing students. This instrument was the most comprehensive instrument found. It assessed the broad concept of safe medication administration, and included a detailed description of development and establishment of validity and reliability using Rasch measurement. Ryan reported evidence of content validity, fit validity and reliability of separation.

\subsection{Summary of instruments presented}

Based on this review, there is a paucity of instruments in the printed literature to assess safe medication administration. One concern is that the majority of the instruments found in the articles only assessed one aspect of safe medication administration. Another concern is the varying levels of evidence of validity and reliability mentioned in the articles.

\section{Study methods}

A survey was conducted to identify strategies or instruments used by faculty to elicit information on how safe medication administration was assessed in pre-licensure nursing education. The specific research questions addressed in the survey were: 1) How is safe medication administration assessed prior to students entering the clinical area; 2) How is safe medication administration assessed during clinical; 3) How is knowledge of "right drug" assessed in the classroom and 4) How is knowledge of "right dose" assessed in the classroom setting. 


\subsection{Survey instrument development}

A survey instrument was developed for this study based upon the results of the literature review and the five rights of safe medication administration (see Appendix for survey instrument). The survey is comprised of 14 questions that address the four research questions; the majority of the questions were closed-ended questions requiring the participants to mark all that apply. A few questions allowed the respondents to simply answer the question. A summary of the relationship between the four research questions and the 14 survey questions is found in Table 2.

Table 2. Development of Survey Questionnaire Based on Research Questions

\begin{tabular}{|c|c|}
\hline Research Question & Survey Question \\
\hline $\begin{array}{l}\text { 1. How is safe } \\
\text { medication } \\
\text { administration assessed } \\
\text { prior to students } \\
\text { entering the clinical area }\end{array}$ & $\begin{array}{l}\text { 4. Please identify which of the following methods are used in your nursing program to assess the } \\
\text { baccalaureate students' ability to administer medications safely prior to administering medications in the } \\
\text { clinical setting. Mark all that apply. } \\
\text { 12. Is a specific "performance checklist" for safe medication administration used in the skills laboratory, } \\
\text { clinical or both in your nursing program? } \\
\text { 13. Is there anything else you would like to include to better describe how your nursing program assesses } \\
\text { its baccalaureate students for safe medication administration? } \\
\text { 14. Would you be comfortable sharing any of your assessments with the researcher (such as the } \\
\text { performance checklist, exams, etc)? If so, please copy the document into the space below, email or send } \\
\text { via postal service to the researcher. }\end{array}$ \\
\hline $\begin{array}{l}\text { 2. How is safe } \\
\text { medication } \\
\text { administration assessed } \\
\text { during clinical }\end{array}$ & $\begin{array}{l}\text { 5. Please identify which of the following methods are used in your nursing program to assess the } \\
\text { baccalaureate students' ability to administer medications safely while in the clinical setting. Mark all } \\
\text { that apply. } \\
\text { 12. Is a specific "performance checklist" for safe medication administration used in the skills laboratory, } \\
\text { clinical or both in your nursing program? } \\
\text { 13. Is there anything else you would like to include to better describe how your nursing program assesses } \\
\text { its baccalaureate students for safe medication administration? } \\
\text { 14. Would you be comfortable sharing any of your assessments with the researcher (such as the } \\
\text { performance checklist, exams, etc.)? If so, please copy the document into the space below, email or send } \\
\text { via postal service to the researcher. }\end{array}$ \\
\hline $\begin{array}{l}\text { 3. How is knowledge of } \\
\text { "right drug" assessed in } \\
\text { the classroom }\end{array}$ & $\begin{array}{l}\text { 4. Please identify which of the following methods are used in your nursing program to assess the } \\
\text { baccalaureate students' ability to administer medications safely prior to administering medications in the } \\
\text { clinical setting. Mark all that apply. } \\
6 \text {. Who teaches the pharmacology course content in your nursing program to baccalaureate nursing } \\
\text { students? Mark all that apply. } \\
\text { 13. Is there anything else you would like to include to better describe how your nursing program assesses } \\
\text { its baccalaureate students for safe medication administration? }\end{array}$ \\
\hline
\end{tabular}

The content validity of the survey was evaluated initially by a total of seven faculty at one public and two independent nursing education programs. Content reviewers were sent the survey and asked to review it for clarity of questions and answer options. In addition, they were asked to consider whether the survey captured how the competency of safe medication administration was assessed in nursing education. The experts were also asked to provide suggestions on whether additional questions were needed in the survey. Following review by the content experts, the survey was refined slightly by rewriting selected questions and by the addition of answer options for selected questions. The final version of the survey was completed by both the Dean and Associate Dean of Nursing at an independent university prior to 
distributing the questionnaire to the entire sample. Due to their involvement in development of the survey, this program was eliminated from participating in the study.

\subsection{Sampling methods}

The Dean or Program Director of every American Association of Colleges of Nursing (AACN) member schools that offers a BSN was invited to participate in the study. AACN membership includes programs from all 50 states, Washington D.C., Puerto Rico, online programs and international programs, totaling over 640 programs ${ }^{[22]}$. The sample was obtained through an e-mail list and included over 600 email addresses.

\subsection{Procedure}

Following Institution Review Board approval, the survey was placed online on a secured survey system, WebSurveyor. The Deans or Directors of the AACN BSN schools were emailed three separate times at designated intervals over the course of a semester. Participation was voluntary; consent was indicated by completion of the survey.

\subsection{Data analysis}

Data analysis was completed using an appropriate statistical software package, SPSS. The fourteen questions in the survey yielded nominal, frequency and ordinal data. Descriptive statistics are presented for each item of the survey.

\section{Results}

Over 100 emails were returned as undeliverable after the first email was sent; the researcher then went to the program's website to verify the correct email address for the Dean or Director. Following the second email, many emails were still returned as undeliverable indicating that the program's website did not list the correct email address for their Dean/Director.

Over 80 programs sent a reply email indicating their program was a BSN completion program (also known as RN to BSN program) and did not assess safe medication administration, thus the survey was not applicable to their education program; and they were removed from the email list. One program sent a reply email that their program was new and they did not have any nursing students beyond freshmen standing, thus the survey was not applicable to them as they had yet to assess safe medication administration in their nursing students. Five programs sent a reply email and requested to be removed from the email list and stated they would not be participating; some offered an explanation that they simply didn't have the time to respond to all the survey requests they receive each year. Ten programs responded to the emails asking if the researcher had obtained IRB approval at their institution and stated they would not be able to participate unless this was done. The researcher elected not to request IRB approval at each program's institution and offered to email the letter indicating IRB approval had been obtained at the researcher's institution.

The third email was sent to 457 email addresses; the final sample reflects data gathered from 239 programs that agreed to participate and submitted survey responses. It is estimated that there were 450 applicable programs for this study; the participation rate for this study was 53\%. After reviewing the responses, none were deemed ineligible for any reason and all were included in the data analysis. However, some participants left questions blank on the survey rather than select the "unsure” option.

The first three questions of the survey collected demographic information. Of the 239 programs that participated, $47.3 \%$ $(\mathrm{N}=112)$ identified their program as being a part of an independent institution and 52.7\% ( $\mathrm{N}=125)$ identified their program as being a part of a public institution. Two participants chose not to provide this information. Ninety-six percent indicated they offered a BSN; a few offered a BA with a major in nursing. Over $63 \%$ of the programs $(\mathrm{N}=152)$ also offered a graduate nursing degree including a Master's in nursing, Doctorate in Nursing Practice or a Doctorate in Nursing. The 
programs varied in size with the smallest graduating 12 BSN students annually and the largest graduating 800 BSN students; the mean number of BSN students that graduated annually from the programs that participated was 111 . Data from the 2010-2011 AACN report on baccalaureate enrollment indicates that there were 51,039 graduates from 608 generic (entry-level) baccalaureate nursing program from August 1, 2009 to July 31, 2010; each program had an average of 84 graduates ${ }^{[23]}$. The Report did not provide a range for the number of graduates. While the reported average number of baccalaureate graduates is smaller than that reported by the sample, this may be due to recent enrollment increases. The participants were instructed to report the average number of baccalaureate students they graduate each year; this may have been based upon their current enrollment, rather than actual number they most recently graduated. This supports the generalizability of the data found in the present study as the average size of the sample is representative of the population of AACN BSN programs.

\subsection{Research question one}

The first research question asked how safe medication administration was assessed prior to students entering the clinical area and the participants could select as many answers as applied. Based on the individual item responses for this survey question, $60 \%(\mathrm{~N}=144)$ used the successful completion of a stand-alone pharmacology course, 36.8\% ( $\mathrm{N}=88$ ) used successful completion of nursing course(s) that integrate pharmacology content, 29.3\% ( $\mathrm{N}=70)$ used computer-assisted safe medication administration module and exam, 85.4\% ( $\mathrm{N}=204)$ used examinations that included questions on safe medication administration, 96.2\% percent of the programs $(\mathrm{N}=230)$ indicated they used medication calculation / mathematical exams, 95\% ( $\mathrm{N}=227)$ used performance assessment in skills laboratory on medication administration, 54.8\% ( $\mathrm{N}=131)$ used performance assessment prior to clinical, and 5.4\% ( $\mathrm{N}=13)$ indicated "other" (see Figure 1). Specific comments in the "other" response option included: concurrent enrollment in pharmacology $(\mathrm{N}=4)$ and simulation $(\mathrm{N}=6)$. The most commonly used assessment strategy prior to students entering the clinical area was the use of a medication calculation / mathematical exam.

\subsection{Research question two}

The second research question asked how safe medication administration is assessed in the clinical setting; participants could select as many answers as applied. Ninety-three percent $(\mathrm{N}=223)$ used oral review with the clinical instructor, $90 \%$ $(\mathrm{N}=215)$ used performance assessment during clinical, 49.8\% ( $\mathrm{N}=119)$ used a written assignment, 1.3\% ( $\mathrm{N}=3)$ were unsure, and 4.2\% ( $\mathrm{N=10}$ ) indicated "other" (see Figure 2). Specific comments in the "other" response option included: simulation $(\mathrm{N}=2)$, $\mathrm{PDA} / \mathrm{i}$ Touch $(\mathrm{N}=2)$, and preceptor $(\mathrm{N}=4)$. The most commonly used assessment strategy was oral review with the clinical instructor.

Figure 1. Data for Research Question One

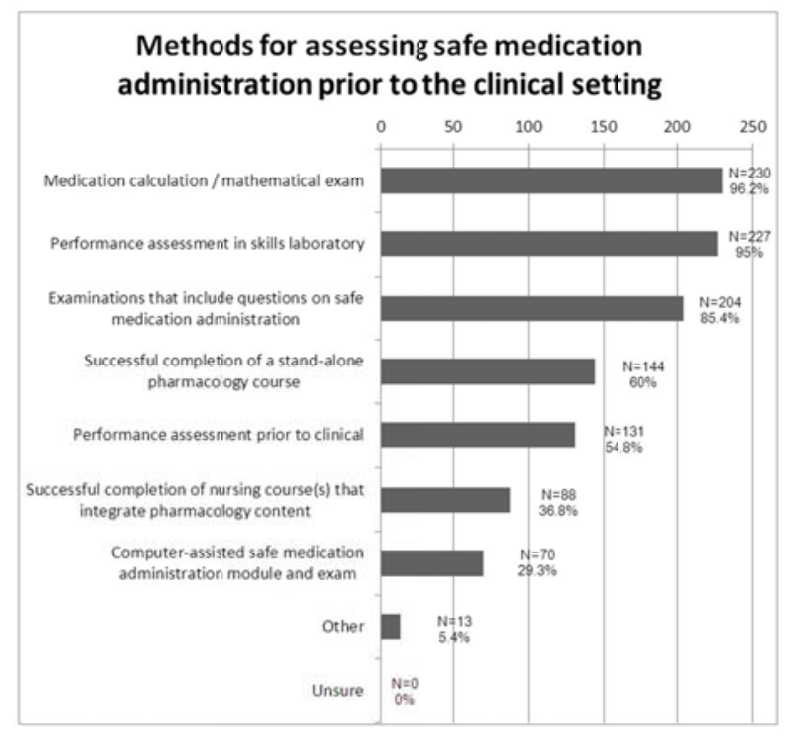


Figure 2. Data for Research Question Two

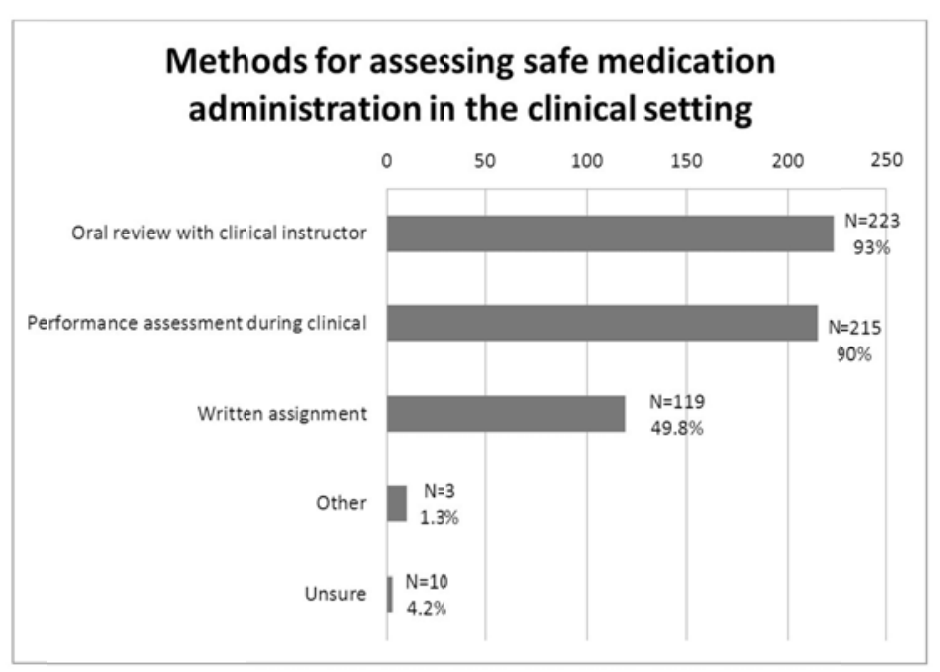

\subsection{Research question three}

The third research question was about assessment of "right drug” in the classroom, specifically asking who taught the pharmacology course and participants could select as many answers as applied. Of those that responded, eighty-nine percent $(\mathrm{N}=213)$ used nursing faculty with a nursing degree, 16.3\% of the participants $(\mathrm{N}=39)$ indicated that a faculty member who was not a nurse taught the pharmacology content. As stated in the results of research question one, a variation was evident with regards to the placement of pharmacology content with respect to whether it is prior to students entering the clinical setting.

\subsection{Research question four}

The fourth research question was about assessment of "right dose" in the classroom. One item for this question asked about the use of a medication calculation or mathematical exam including how frequently it is administered to nursing students; participants could select only one answer. Of those that responded, fifty percent $(\mathrm{N}=116)$ indicated a medication calculation or mathematical exam was done each semester, 20.7\% ( $\mathrm{N}=48)$ indicated this was integrated into every nursing exam, 7.3\% ( $\mathrm{N}=17)$ indicated this is done annually, 6.5\% $(\mathrm{N}=15)$ indicated this is only done once during the entire nursing program, 13.4\% $(\mathrm{N}=31)$ responded with “other," 2.2\% ( $\mathrm{N}=5)$ were unsure, and 2.9\% ( $\mathrm{N}=7$ ) did not provide a response (Figure 3). None of the participants chose to complete the "other" option for this question.

Figure 3. Data for Research Question Four

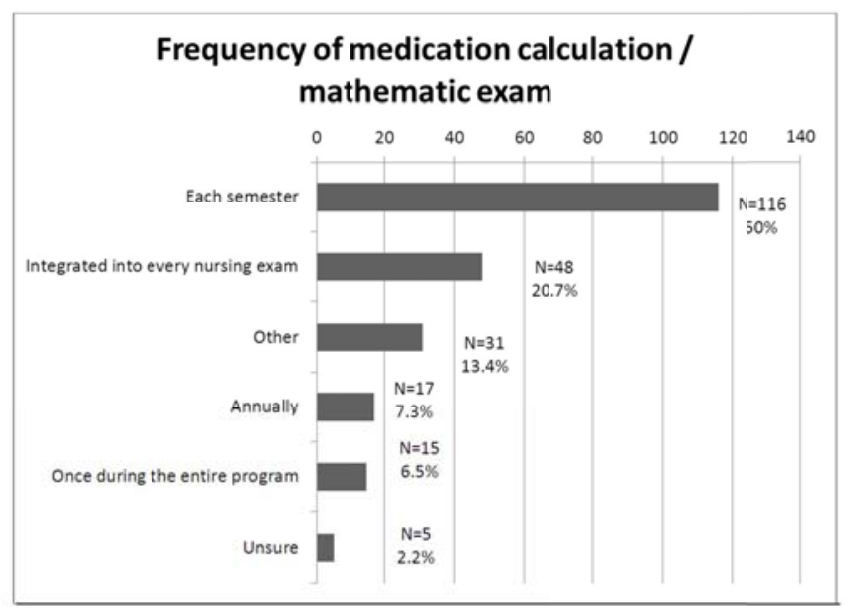


The second component of this question was open-ended and asked the participants to provide the "passing" percentage grade to be achieved on the examination. Of those participants that chose to respond the breakdown was as follows: passing percentage grade varied between $70-100 \%$. The individual responses were: $4.5 \%(\mathrm{~N}=10)$ required between 70-79\%, 21.9\% ( $\mathrm{N}=49$ ) required between $80-89 \%, 43.8 \%(\mathrm{~N}=98)$ required between $90-99 \%$ and $29.5 \%(\mathrm{~N}=66)$ required $100 \%$ on the medication calculation exam in order to "pass." Sixteen participants did not answer this item. Two respondents provided narrative information indicating that the passing percentage grade varied based upon the nursing students academic level in the program.

The third item for this question was open-ended and asked what type of remediation was required for non-passing performance. Remediation for non-passing grades varied greatly with the most common type of remediation included meeting with faculty, lab coordinator, or math tutor $(\mathrm{N}=48)$. The second most common type of remediation included the use of computers, including Evolve and Elsevier textbook websites, ATI review, Kaplan review or other computer modules ( $\mathrm{N}=34)$. Most programs indicated that students who did not pass the exam retook it at least once $(\mathrm{N}=105)$. Three programs specified that if the student did not pass it after three retakes then there was an automatic course failure or program dismissal. One program indicated the student could retake the exam as many times as needed in order to achieve a passing grade.

The last item for this question asked if the medication calculation exam was developed by faculty of the nursing education program. Of those who responded, $90.6 \%(\mathrm{~N}=213)$ indicated yes, $6.4 \%(\mathrm{~N}=15)$ indicated no, and 3\% $(\mathrm{N}=7)$ were unsure.

\section{Discussion}

To summarize the results of the survey, it was found that there was no standardized method for assessing safe medication administration. The data for the first research question demonstrated the most frequently used assessment strategy by the nursing programs was the medication calculation / mathematical exam, which assesses knowledge and performance of right dose. This echoes the findings of the literature search in that most of the instruments found in the literature related to safe medication administration were medication calculation or mathematical exams and focused on the calculation of right dosage. The other two most common forms of assessing safe medication administration prior to clinical were a "performance assessment" with one specifically stating it occurred in the skills laboratory. It is unclear if this is a comprehensive assessment of all aspects of safe medication administration, or if it is an assessment of just some of the parts of safe medication administration, such as correctly drawing up a medication from a vial into a syringe.

The data for the second research question demonstrated that the vast majority of nursing education programs required the instructor's presence when assessing safe medication administration in the clinical setting. This is concerning because of increased demands on the instructor during clinical, increasing size of clinical groups, and the increasing acuity of patients, all of which impact the quality of the educational experience for the nursing students. It is recommended students are allowed sufficient opportunities to practice and have their skill performance assessed prior to entering the clinical setting. This is beneficial to the nursing students, and it is also beneficial to the patient that the student has already practiced and been assessed prior to providing patient care.

The data for the third research question for the programs that responded indicated a variation in who teaches the pharmacology course and when it is placed in the program. If non-nurses are solely teaching the pharmacology course, there may be some question as to whether the course includes the nursing implications of pharmacology and safe medication administration. One respondent provided narrative information at the end of the survey stating that placement of the pharmacology course is a current area of debate, and it is presently placed concurrently with the first clinical course, and that students are administering medications in clinical prior to successful completion of the pharmacology course. Another respondent provided narrative information indicating that the pharmacology course is placed concurrently with "Fundamentals" during the nursing student's sophomore year. It is clear that not all programs require successful 
completion of a pharmacology course prior to entering the clinical setting. Therefore, nursing students may be administrating medications without sufficient assessment of their knowledge of "right drug."

The data for the fourth research question demonstrated much variation in the frequency of the medication calculation / mathematical exam being administered in the nursing programs, what constituted a passing percentage grade for the examinations, and what type of remediation was required for non-passing grades. In addition, the vast majority indicated that the medication calculation exam was developed by the nursing program's faculty. This practice raises the question whether the medication calculation exam have been psychometrically evaluated, although the survey did not directly pose this question.

One limitation of the present study is related to the newness of the survey. Meaningful responses came out of the "other" answer response in which participants were able to add additional comments, such as how many times students were allowed to retake a medication calculation exam or whether a program would ever dismiss students due to their inability to successfully pass the medication calculation exam. As this information was not specifically asked in the survey, it is difficult to interpret the data in the context of descriptive study. The survey should be further refined to add additional answer options that were provided in the "other" answer option in order to obtain additional descriptive data that could be analyzed for frequency trends.

Another limitation was the uncertainty as to how many nursing education programs were eligible to participate and the lack of complete or accurate e-mails addresses to enable the researcher to directly contact every BSN program. It is impossible to determine survey response rate without knowing how many nursing education programs were eligible. Also, despite the multiple attempts to contact all BSN Deans and Directors, some programs may not have received their invitation to participate in the study. In addition, some nursing education programs websites were difficult to navigate and were time-intensive in order to discover who the Dean or Director was, and to find their email address. If the study were to be repeated, the researcher may want to incorporate phone calls with the solicitation of surveys via e-mail. This approach may enable the researcher to have a more accurate list of emails.

\section{Conclusions and recommendations}

The call has been made by QSEN for all nursing education programs to integrate safety into the curriculum. While the knowledge, skill, and attitude (KSA's) for safety have been outlined by QSEN, assessments for this competency and more specifically, safe medication administration are lacking. Further comprehensive assessments of safe medication administration are needed in order to evaluate whether nursing students have the KSA's and to evaluate various teaching strategies. Assessments should be all-inclusive to safe medication administration and not just focus on assessment of one of the five rights. Lastly, assessments of safe medication administration should have evidence of validity and reliability.

There is an overwhelming need for a comprehensive assessment of safe medication administration that can be used prior to the clinical setting, as it is vital to ensure nursing students are prepared to provide safe care. In addition, a comprehensive assessment of safe medication administration could be used to evaluate various teaching strategies.

\section{Acknowledgement}

I would like to acknowledge Dr. Elizabeth Swanson from the University of Iowa, College of Nursing for her support and continued assistance with the manuscript. I would also like to acknowledge faculty from my Writing Circle at the University of Nebraska, Medical Center College of Nursing who assisted with critical revision of the manuscript. 


\section{References}

[1] The Joint Commission (2008, April 11). Preventing pediatric medication errors. Sentinel Event Alert [Internet]. May 4, 2009. Available from: http://www.jointcommission.org/sentinelevents/sentineleventalert/sea_39.htm

[2] Kohn, L., Corrigan, J., Donaldson, M. (Editors). To err is human: Building a safer health system. Washington DC: National Academy Press. 2000

[3] Cronenwett, L., Sherwood, G., Barnsteiner, J., Disch, J., Johnson, J., Mitchell, P., Warren, J. Quality and safety education for nurses. Nursing Outlook. 2007; 55(3), 122-131. http://dx.doi.org/10.1016/j.outlook.2007.02.006

[4] Quality and Safety Education for Nurses [Internet]. Retrieved September 12, 2011. Available from: from http://www.qsen.org/

[5] Bulecheck, G., Butcher, H., Dochterman, J. (Eds). Nursing Interventions Classification (NIC) (5th ed.) St. Louis: Mosby/Elsevier 2008.

[6] National Coordinating Council for Medication Error Reporting and Prevention [Internet]. Retrieved March 29, 2009. Available from: http://www.nccmerp.org

[7] National Coordinating Council for Medication Error Reporting and Prevention. (1999, June 29). Recommendations to enhance accuracy of administration of medications [Internet]. Retrieved March 29, 2009. Available from: http://www.nccmerp.org/ council/council1999-06-29.html

[8] Ashby, D. A. Medication calculation skills of the medical-surgical nurse. MEDSURG Nursing. 1997; 6(2): 90-94. PMid: 9238978

[9] Bayne, T., Bindler, R. Medication calculation skills of registered nurses. Journal of Continuing Education in Nursing. 1988; 19(6): 258-262. PMid: 3144564

[10] Bayne, T., Bindler, R. Effectiveness of medication calculation enhancement methods with nurses. Journal of Nursing Staff Development. 1997; 13(6): 293-301. PMid: 9429370

[11] Bindler, R., Bayne, T. Do baccalaureate students possess basic mathematics proficiency? Journal of Nursing Education. 1984; 25(5): 192-197.

[12] Bindler, R., Bayne, T. Medication calculation ability of registered nurses. Image: Journal of Nursing Scholarship. 1991; 23(4): 221-224. http://dx.doi.org/10.1111/j.1547-5069.1991.tb00675.x

[13] Bliss Holtz, J., Bliss-Holtz, J. Medication dosage calculation test--form I. Nursing Research.1994; 43: 373-375. PMid: 7971303

[14] Flynn, J. M., Moore, J. B. Predictors of nursing students' math performance. Western Journal of Nursing Research, 1990; 12(4): 537-545. PMid:2375104 http://dx.doi.org/10.1177/019394599001200409

[15] Kohtz, C. Gowda, C. Teaching drug calculation in nursing education: A comparison study. Nurse Educator. 2010; 35(2): 83-86. PMid:20173596 http://dx.doi.org/10.1097/NNE.0b013e3181ced8a8

[16] Rainboth, L, DeMasi, C. Nursing students' mathematic calculation skills. Nurse Education in Practice. 2006; 6: 347-353. PMid: 19040901 http://dx.doi.org/10.1016/j.nepr.2006.07.017

[17] Serembus, J. F. Medication calculation ability of baccalaureate nursing students as a function of method of instruction. (Doctoral Dissertation). Retrieved from ProQuest. 2000. (UMI Number 9998872).

[18] Ndosi, M. E., Newell, R. Nurses' knowledge of pharmacology behind drugs they commonly administer. Journal of Clinical Nursing. 2009; 18(4): 570-580. http://dx.doi.org/10.1111/j.1354-2702.2008.02290.x

[19] Hsaio, G., Chen, I., Yu, S., Wei, I., Fang, Y., Tang, F. Nurses' knowledge of high-alert medications: Instrument development and validation. Journal of Advanced Nursing. 2010; 66(1): 177-190. PMid: 20423443 http://dx.doi.org/10.1111/j.1365-2648.2009.05164.x

[20] Werab, B., Alexander, C., Brunt, B., Wester, F. The use of medication modules for medication administration problems. Journal of Nursing Staff Development. 1994; 10(1): 16-21. PMid:8120641

[21] Ryan, D. Measurement of student nurse performance in safe administration of medication. (Doctoral dissertation). Retrieved from ProQuest. 2007. (UMI Number 3279892).

[22] American Association of Colleges of Nursing [Internet]. Retrieved June 1. 2010. Available from: http://www.aacn.nche.edu/

[23] Fang, D., Hu, E., Badnash, G.D. 2010-2011 Enrollment and Graduations in Baccalaureate and Graduate Programs in Nursing. Washington, DC: American Association of College of Nursing. 2007. 